\title{
NOTE
}

\section{Response of Testis to Androgen and Gonadotropins in Neonatally Estrogenized and Androgenized Mice}

\author{
YASUHIKo OHTA \\ Biology Department, Kawasaki Medical School \\ Kurashiki-shi Okayama 701-01, Japan
}

\begin{abstract}
Synopsis
Male mice of the $\mathrm{C} 3 \mathrm{H} / \mathrm{Tw}$ stain were given 15 daily injections with estradiol-17 $\beta$ (E), $30 \mu \mathrm{g} / \mathrm{day}$, or testosterone propionate (TP), $50 \mu \mathrm{g} /$ day for the first 10 days and $100 \mu \mathrm{g} /$ day for the following 5 days, from the day of birth, which were followed by 30 daily injections with TP, TP plus PMS or PMS plus HCG. Daily doses of hormones were increased with advancing age, $50 \mu \mathrm{g}$ (for the first 5 days), $100 \mu \mathrm{g}$ (for the middle 15 days) and $200 \mu \mathrm{g}$ (for the last 10 days) for TP, and 10 IU (for the first 5 days), 15 IU (for the next 15 days) and $30 \mathrm{IU}$ (for the last 10 days) for gonadotropins. The control mice received oil and saline after neonatal treatment with $\mathrm{E}$ or TP. When sacrificed on the day following the last injection, the controls had small testes without spermatogenesis and underdeveloped seminal vesicles. Especially, in one of the neonatally estrogenized mice, one of the testes was markedly damaged. Injections of TP, TP plus PMS or PMS plus HCG for 30 consective days restored the testicular activities in neonatally androgenized mice. Although the testes were smaller than in the controls given neonatal oil injections, active spermatogenesis was going on in a majority of the seminiferous tubules. By contrast, injections of TP and/or gonadotropins failed to restore normal spermatogenesis in a majority of the neonatally estrogenized mice, about 20 to $30 \%$ of the animals having one or both testes severely damaged. However, interstitial cells of the testes underwent hypertrophy and hyperplasia in response to the gonadotropin injections in animals given either $\mathrm{E}$ or TP neonatally, although the stimulation was slight in those given neonatal TP followed by TP plus PMS. The seminal vesicles grafted from infantile males into neonatally estrogenized mice were androgenically stimulated when recovered after injections of gonadotropins for 25 days. Leydig cells of the hosts' own testes were hypertrophied. However, as in neonatally estrogenized mice given injections of androgen, the hosts' glands remained atrophic, containing no secretion in the lumen.
\end{abstract}

In male mice, neonatal administration of estrogen or androgen for 10-15 days from the day of birth exerts an inhibitory effect on the development of the testis and the accessory organs (Mori, 1967; Ohta, 1976). Mori (1967) showed a permanent or, at least, a long-lasting interference with spermatogenesis in neonatally estrogenized mice. Takasugi (1970) also reported testi-

Received for publication November 11, 1976. cular lesions in neonatally estrogenized adult mice. On the basis of their findings that the seminiferous tubules were damaged to some extent in the mouse testis during or shortly after the neonatal estrogen treatment, Ohta and Takasugi (1974) suggested a direct action of estrogen on the neonatal testes. However, Ohta (1976) pointed out that neonatal androgenization in mice brought about neither complete arrest of spermatogenesis nor destructive changes in male ac- 
cessories in adulthood, although the onset of spermatogenesis was significantly delayed as compared with the control animals (Ohta, 1976).

It was recently shown that after 60-day residence in the testes of normal adults, testes grafted from neonatally estrogenized infantile mice as well as from the oil controls invariably contained well-developed seminiferous tubules and Leydig cells (Ohta, 1975). However, the modes of action of gonadal steroids administered neonatally on the testicular function have not yet been thoroughly worked out. Accordingly, androgen and/or gonadotropins were administered after the neonatal treatment with estrogen or androgen, for the purpose of investigating the nature of the effects of the neonatal treatments on the testes of neonatal mice.

\section{Materials and Methods}

Male mice of the $\mathrm{C} 3 \mathrm{H} / \mathrm{Tw}$ strain used in these experiments were raised in a light- $(14 \mathrm{hr}$ of light, $10 \mathrm{hr}$ of darkness) and temperature-controlled room. They were fed with a standard laboratory chow and water ad libitum.

Fifty-five males were given daily subcutaneous injections with $30 \mu \mathrm{g}$ estradiol-17 $\beta$ (E) in $0.02 \mathrm{~m} l$ sesame oil for 15 days starting on the day of birth. Thirtyfive other males were given neonatal injections with testosterone propionate (TP) for 15 days after birth, daily doses being $50 \mu \mathrm{g}$ in $0.02 \mathrm{ml}$ oil for the first 10 days and $100 \mu \mathrm{g}$ in $0.04 \mathrm{ml}$ oil for the next 5 days. Ten other mice given daily injections with sesame oil only in comparable amounts for 15 postnatal days served as the controls. On the day following the last injection of E or TP, the two types of animals were respectively divided into 4 groups and given 30 daily injections with either TP (Groups $C$ and $G$ ), TP plus PMS (Primantron, Schering A. G., Berlin) (Groups D and H), PMS plus HCG (Primogonyl, Schering A. G., Berlin) (Groups E and I), or oil plus saline vehicles (Groups B and F). The androgen and gonadotropins were injected subcutaneously at different sites of the body. Daily doses were increased with advancing age, $50 \mu \mathrm{g}$ TP (in $0.02 \mathrm{~m} l$ sesame oil), $50 \mu \mathrm{g}$ TP plus $10 \mathrm{IU}$ PMS (in $0.02 \mathrm{ml}$ saline) and 10 IU PMS plus $10 \mathrm{IU}$ HCG (together in $0.02 \mathrm{ml}$ saline) for the first 5 days, $100 \mu \mathrm{g}$ TP (in $0.04 \mathrm{ml}$ ), $100 \mu \mathrm{g}$ TP plus $15 \mathrm{IU}$ PMS (in $0.03 \mathrm{ml}$ ) and $15 \mathrm{IU}$ PMS plus $15 \mathrm{IU}$ HCG (in $0.03 \mathrm{ml}$ ) for the middle
15 days and $200 \mu \mathrm{g}$ TP (in $0.08 \mathrm{ml}$ ), $200 \mu \mathrm{g}$ TP plus $30 \mathrm{IU}$ PMS (in $0.06 \mathrm{ml}$ ) and $30 \mathrm{IU}$ PMS plus $30 \mathrm{IU}$ HCG (in $0.06 \mathrm{ml}$ ) for the last 10 days. On the 5 th day of the PMS-HCG treatment, 6 of 14 estrogenized mice of Group E received subcutaneous transplants, under the abdominal skin, of seminal vesicles together with coagulating glands from normal mice aged 15-20 days. All animals were sacrificed at 45 days of age after being weighed.

At autopsy, testes and seminal vesicles together with coagulating glands were dissected out, weighed and fixed in Bouin's solution. Sections were cut in paraffin at $8 \mu \mathrm{m}$ and stained with Delafield's hematoxylin and eosin.

In 5 transverse sections randomly selected from each testis, 20 sections of seminiferous tubules were carefully examined. Spermatogenic index (\%) for each mouse was estimated by the number of tubules containing mature spermatozoa per 200 tubules (Takasugi and Furukawa, 1972).

\section{Results}

Testes and seminal vesicles in 45-day-old mice given neonatal injections with oil vehicle only

The testes consisted of seminiferous tubules with active spermatogenesis and normally developed interstitial tissues (Fig. 1). Clumps of Leyding cells were seen in angular interstices between the tubules. The mean spermatogenic index was $67.5 \pm 1.3$ (Table 1).

The seminal vesicles contained a large amount of eosinophilic secretion in the lumen. The epithelium was composed of high columnar cells bearing numerous granules in the supranuclear regions of the cytoplasm.

Testes and seminal vesicles in 45-day-old mice given 30 daily injections with TP, TP plus PMS, PMS plus HCG or oil plus saline following neonatal estrogenization

The testes were significantly smaller in weight in the mice given injections with oil plus saline for 30 days starting on the day following the last injection of $\mathrm{E}$ (Group B) than in the oil controls (Group A) $(p<0.01)$. In one of 14 animals, both seminiferous tubules and interstitial tissue in one of the 
Table 1. Organ weights and spermatogenic indices in 45-day-old, neonatally estrogenized and androgenized mice given oil plus saline, testosterone propionate (TP), TP plus PMS and PMS plus HCG for 30 days.

\begin{tabular}{|c|c|c|c|c|c|}
\hline \multirow[b]{2}{*}{ Group } & \multirow[b]{2}{*}{ Treatment } & \multirow[b]{2}{*}{$\begin{array}{l}\text { No. of } \\
\text { mice }\end{array}$} & \multicolumn{2}{|c|}{ Organ weights ( $\mathrm{mg} / 20 \mathrm{~g}$ Body wt.) } & \multirow[b]{2}{*}{$\begin{array}{l}\text { Spermatogenic } \\
\text { index }\end{array}$} \\
\hline & & & Testes & $\begin{array}{l}\text { Seminal vesicles plus } \\
\text { coagulating glands }\end{array}$ & \\
\hline \multicolumn{6}{|c|}{ Oil control } \\
\hline A & - & 10 & $131.2 \pm 3.5^{*}$ & $121.2 \pm 8.4$ & $67.5 \pm 1.3$ \\
\hline \multicolumn{6}{|c|}{ Neonatally estrogenized } \\
\hline $\mathbf{B}$ & oil + saline & 14 & $53.3 \pm 2.9$ & $9.2 \pm 0.6$ & 0 \\
\hline $\mathrm{C}$ & TP & 13 & $31.6 \pm 1.6$ & $26.1 \pm 1.9$ & 0 \\
\hline $\mathrm{D}$ & $\mathrm{TP}+\mathrm{PMS}$ & 14 & $49.3 \pm 2.9$ & $34.5 \pm 2.8$ & 0 \\
\hline $\mathrm{E}$ & $\mathrm{PMS}+\mathrm{HCG}$ & 14 & $65.7 \pm 7.9$ & $\begin{array}{l}30.9 \pm 2.9 \\
(60.2 \pm 24.4)^{* *}\end{array}$ & $3.2 \pm 1.8$ \\
\hline \multicolumn{6}{|c|}{ Neonatally androgenized } \\
\hline $\mathrm{F}$ & oil + saline & 8 & $25.6 \pm 3.6$ & $10.3 \pm 0.9$ & 0 \\
\hline $\mathrm{G}$ & TP & 9 & $56.1 \pm 1.5$ & $171.1 \pm 6.9$ & $56.7 \pm 1.4$ \\
\hline $\mathrm{H}$ & $\mathrm{TP}+\mathrm{PMS}$ & 9 & $80.9 \pm 2.6$ & $165.3 \pm 3.2$ & $61.7 \pm 1.0$ \\
\hline I & $\mathrm{PMS}+\mathrm{HCG}$ & 9 & $101.5 \pm 2.9$ & $181.4 \pm 7.5$ & $63.1 \pm 1.5$ \\
\hline
\end{tabular}

* Mean \pm standard error.

** Mean weight of 6 grafts of seminal vesicle plus coagulating gland from normal infantile mice is given in parentheses.

testes were highly damaged. The germinal epithelium was disorganized in a majority of the tubules, the tubular lumen being infiltrated with numerous leucocytes. Intertubular spaces were largely occupied by proliferated fibroblasts, some of which were undergoing fatty degeneration. Diffuse infiltration of leucocytes took place among the fibroblasts. Tubules of the contralateral testis of this mouse also contained neither spermatids nor spermatozoa. Some small clumps of Leydig cells undergoing atrophy were encountered in intertubular spaces. In 3 other mice, both seminiferous tubules and interstitial tissue were not so severely affected in either testis, although the germinal epithelium had become lowered in height, completely lacking spermatids and spermatozoa (Fig. 2).

The testes of the remaining 10 mice were less severely affected. However, the seminiferous epithelium of both testes consisted mainly of spermatogonia and spermatocytes. The mean spermatogenic index for the 14 mice of this group was 0 (Table 1). The seminal vesicles were reduced in size. The lumen lined by a thin epithelium contained no colloidal secretion. The metaplasia took place in some parts of the epithelium. The stromal tissue was proliferated.

The testes from 2 groups of neonatally estrogenized mice, Group D given 30 daily injections with TP plus PMS and Group E treated with PMS plus HCG, were not significantly different in mean weight from those of estrogenized mice given oil plus saline (Group B) $(0.1<\mathrm{p}<0.2$ and $0.2<$ $\mathrm{p}<0.4$, respectively). However, the testes from Group $C$ mice given TP were significantly smaller than those from Group B mice (Table $1, p<0.01$ ). In the testes of 2 of 14 mice from Group E, the germinal epithelium appeared normal in histological structure (Fig. 4). The spermatogenic indices for these 2 mice were 27.0 and 17.0, respectively. In 4 other mice of this group, a majority of the tubules contained healthylooking spermatids, except for 2 mice in which one of the testes was severely injured.

By contrast, the groups given TP (Group C) or TP plus PMS (Group D) had no spermatozoa in the seminiferons tubules. In 3 of 13 group C and 2 of 14 Group D mice, however, many spermatids were present in 


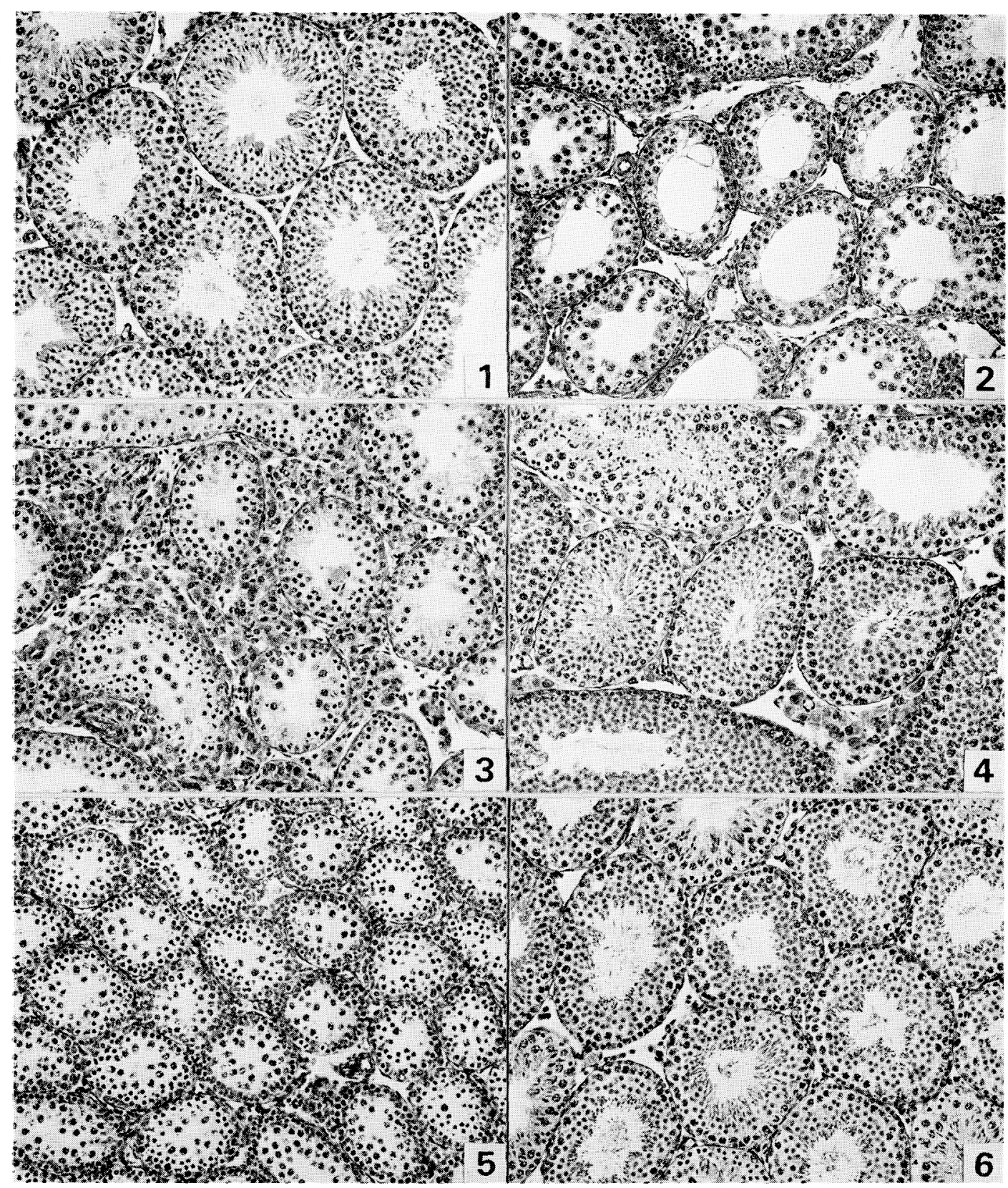

Fig. 1. Testis of a 45-day-old mouse given 15 daily injections with sesame oil from the day of birth. Active spermatogenesis is going on in seminiferous tubules. $\times 130$.

Fig. 2. Testis of a 45-day-old mouse given injections with oil plus saline for 30 consecutive days following 15 daily injections of estradiol-17 $\beta$ from the day of birth. Degeneration of germinal epithelium is pronounced. $\times 130$.

Fig. 3. Testis of a 45-day-old, neonatally estrogenized mouse given testosterone propionate (TP) plus PMS for 30 days. Neither spermatids nor spermatozoa in seminiferous tubules. Intertubular spaces are occupied by hypertrophied Leydig cells. $\times 130$. 
the well-organized germinal epithelium in the tubules in both testes. In 3 other mice belonging to Groups $\mathrm{C}$ ( 1 mouse) and D ( 2 mice), the germinal epithelium appeared healthy showing numerous spermatids in one testis, while both tubules and interstitium were deteriorated in the other. The testes of the remaining 26 mice of Groups $\mathrm{C}, \mathrm{D}$ and $\mathrm{E}$ were atrophic to varying degrees, as in Group B mice, germ cells at the most advanced stage of spermatogenesis being spermatocytes. In some cases, the germinal epithelium in one ( 1 mouse each of Groups C and D) or both testes (1 mouse of Group C and 2 mice of Group E) were highly disorganized. Connective tissue, with or without leucocyte infiltration, was proliferated in intertubular spaces. The spermatogenic indices for Groups $\mathrm{C}$ and $\mathrm{D}$ mice were 0 , in contrast to $3.2 \pm 1.8$ for Group E mice (Table 1).

In the testes of the mice treated with TP plus PMS or PMS plus HCG, except for those with lesions, the interstitial tissue was stimulated to varying degrees. Regardless of the status of seminiferous tubules, intertubular spaces of one or both testes were largely occupied by hypertrophied Leydig cells in 19 of 29 mice of these groups (Fig. 3). By contrast, interstitial cells remained atrophic in Group $\mathrm{C}$ mice given TP only. The seminal vesicles plus coagulating glands were increased in weight in the mice of Groups C, D and E as compared with those in Group B animals $(p<0.01)$, although they were significantly smaller than those in the oil controls (Group A) $(\mathrm{p}<0.01)$. The epithelium was largely composed of high columnar cells. Some areas underwent metaplasia with or without leucocyte infiltration (Fig. 9). The lumen contained hardly any secretion. In these animals, masses composed of lymphocytes were often encountered among the strongly proliferated connective tissue in the interstitium.

The seminal vesicles together with coagulating glands from normal immature males grafted subcutaneously into mice estrogenized neonatally and given PMS plus HCG before sacrifice were removed 25 days after transplantation. The grafts recovered from 3 recipients exhibiting highly developed Leydig cells in both testes were heavier than their own glands in situ, while those recovered from 3 other recipients having one testis severely affected were smaller in weight than the hosts' glands. The grafts varied in weight from 5.9 to $146.2 \mathrm{mg}$ per $20 \mathrm{~g}$ body weight. All grafts were androgenically stimulated to varying degrees, the lumen being filled with secretion (Fig. 8).

Testes and seminal vesicles in 45-day-old neonatally androgenized mice given 30 daily injections with TP, TP plus PMS, PMS plus HCG or oil plus saline

In mice given a 30-day treatment with oil plus saline following 15 daily injections of TP starting on the day of birth (Group F), the testicular development was markedly inhibited. The testes were significantly decreased in weight as compared with those in Groups A and B mice (Table 1, p < 0.01). The seminiferous tubules of both testes contained neither spermatids nor spermatozoa

Fig. 4. Testis of a 45-day-old, neonatally estrogenized mouse given injections with PMS plus HCG for 30 days. Germ cells at all stages of spermatogenesis are present in germinal epithelium. Clumps of hypertrophied Leydig cells in intertubular spaces. $\times 130$.

Fig. 5. Testis of a 45-day-old mouse given injections with oil plus saline for 30 days after 15-day treatment with TP starting at the day of birth. Germinal epithelium is composed of mainly spermatogonia and spermatocytes. $\times 130$.

Fig. 6. Testis of a 45-day-old, neonatally androgenized mouse given TP plus PMS for 30 days. Seminiferous tubules are normal with active spermatogenesis. Interstitial tissue is inconspicuous. $\times 130$. 


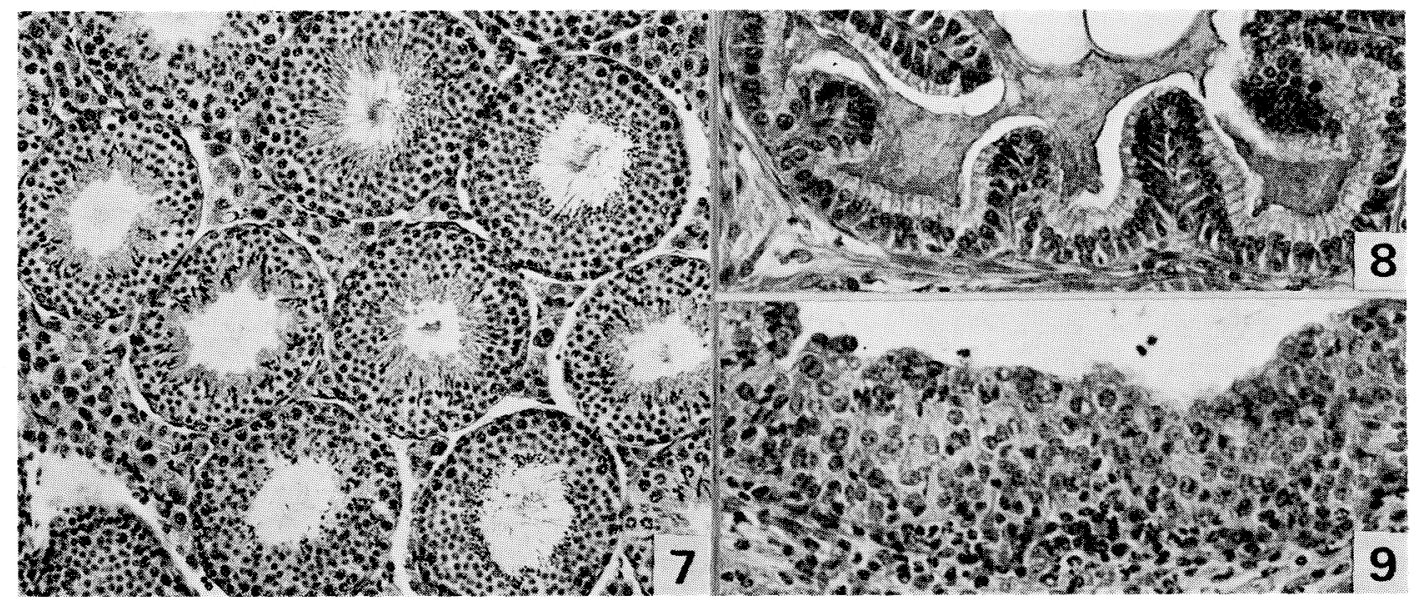

Fig. 7. Testis of a 45-day-old, neonatally androgenized mouse given PMS plus HCG for 30 days. Seminiferous tubules with active spermatogenesis. Interstitial cells developed, $\times 130$.

Fig. 8. Seminal vesicle of a normal infantile mouse after residence as subcutaneous graft in a neonatally estrogenized mouse for 25 days. The host was given injections with PMS plus HCG for 30 days before sacrifice. Colloidal secretion in lumen lined by a high columnar epithelium. $\times 260$.

Fig. 9. Seminal vesicle of a 45-day-old, neonatally estrogenized mouse bearing graft. The mouse was given injections with PMS plus HCG for 30 days. The epithelium is undergoing metaplasia. A number of leucocytes are visible in the epithelium and interstitium. $\times 260$.

(Fig. 5). The interstitial tissue was atrophic. The seminal vesicles were reduced in size, the lumen lined by a low cuboidal epithelium being almost totally devoid of secretion.

After injections of TP (Group G), TP plus PMS (Group $\mathrm{H}$ ) or PMS plus HCG (Group I), the neonatally androgenized mice showed a marked enlargement of the testes and the seminal vesicles plus coagulating glands. The testes were significantly heavier in Group I than in Groups $\mathrm{G}$ and $\mathrm{H}(\mathrm{p}<$ 0.01 ), although the mean testicular weight in Group I was below that in the oil controls (Group A) (Table 1, p<0.01). PMS in combination with TP caused a greater increase in testicular weight that TP alone $(\mathrm{p}<0.01)$. The seminal vesicles plus coagulating glands were much larger in Groups $\mathrm{G}, \mathrm{H}$ and $\mathrm{I}$ than in Group $\mathrm{A}(\mathrm{p}<0.01)$. The glands were approximately the same in mean weight among Groups $\mathrm{G}, \mathrm{H}$ and $\mathrm{I}$.

Histogogical studies revealed that seminiferous tubules of the testes of the mice of Groups G, H and I contained germ cells at all stages of spermatogenesis (Figs. 6 and 7). The mean spermatogenic indices for these mice were $56.7 \pm 1.4,61.7 \pm 1.0$ and $63.1 \pm 1.5$, respectively, in striking contrast to 0 for the neonatally androgenized mice given oil plus saline (Group E). However, these values were significantly smaller than those for the controls given oil injections. neonatally $(p<0.01)$. Differences in the indices between Group I and Group $G$ or $\mathrm{H}$ were statistically significant $(0.01<\mathrm{p}<$ 0.02 and $\mathrm{p}<0.01$, respectively). The interstitial tissue of the testes in Group I mice was well developed, bearing a large number of hypertrophied Leydig cells (Fig. 7). In Groups $\mathrm{G}$ and $\mathrm{H}$, the interstitium exhibited no marked changes, although Leydig cells seemed slightly stimulated in Group H (Fig. 6). The seminal vesicles in these groups of mice were equally developed. The lumina filled with large amounts of secretion were lined by a high columnar epithelium as in the oil controls (Group A). 


\section{Discussion}

After 30 daily injections of oil plus saline, 45-day-old mice which had been given injections with $\mathrm{E}$ or TP for 15 days from the day of birth exhibited atrophic testes and undeveloped seminal vesicles. The germinal epithelium in the seminiferous tubules was almost totally devoid of spermatids and spermatozoa. The interstitial tissue was atrophic. In one testis of one neonatally estrogenized mouse, the tubules were disorganized and the proliferated interstitial tissue was infiltrated with leucocytes. These findings are not in agreement with the results of previous studies (Takasugi, 1970; Takasugi and Furukawa, 1972; Takasugi and Mitsuhashi, 1972; Ohta, 1975) that about $60 \%$ male mice given injections with estrogen for 15 postnatal days exhibited severe damages to one or both testes at 60 days of age. The difference in incidence of the testicular damages may be due to the difference in age of animals at sacrifice (Takasugi, 1970). These results seem to indicate that the secretion of gonadotropins from the anterior pituitary is markedly inhibited in both androgenized and estrogenized mice, until at least 45 days of age. However, the secretion of gonadotropins in androgenized mice appears to increase gradually later (Ohta, 1976).

In neonatally androgenized mice, spermatogenesis was going on in a majority of the tubules when sacrificed after treatment with TP, TP plus PMS or PMS plus HCG, although the spermatogenic activity was lower than in the oil controls. The seminal vesicles in these mice were almost similar in histological structure to those in the oil controls. Recently Ohta (1975) reported that the testes of neonatally estrogenized mice transplanted into scrotal testes of adult mice invariably showed spermatozoa in a good many seminiferous tubules.
The present studies demonstrated, however, that, although a treatment with androgen and/or gonadotropins could stimulate spermatogenesis in neonatally androgenized mice, it failed to restore normal spermatogenesis in a majority of neonatally estrogenized mice. In about 20 to $30 \%$ of the latter, one or both testes were severely damaged. Interstitial cells in the testes of the estrogenized mice given gonadotropins underwent hypertrophy and hyperplasia to varying degrees, while the cells in mice given vehicles only after neonatal estrogenization remained atrophic. The seminal vesicles transplanted from normal infantile mice into neonatally estrogenized mice given PMS plus HCG were androgenically stimulated, while the hosts' own glands remained atrophic as in estrogenized mice treated with TP. Therefore, it seems likely that interstitial cells in neonatally estrogenized mice are capable of developing and secreting androgen in response to continued injections of exogenous gonadotropins following the neonatal estrogen administration. These findings are in harmony with those of Ohta and Takasugi (1974) showing that during and shortly after neonatal estrogen treatment, destructive changes occur in the seminiferous tubules but not in the interstitial tissue of the mouse testis. However, since Oštádalvá et al. (1970) reported that in rats estrogen administered neonatally interfered with metabolism of Leydig cells during their development, it remains to be studied whether the capacity of Leydig cells for synthesizing and secreting androgen in response to gonadotropins is totally unaffected by neonatal estrogen injections. Furthermore, the transplantation experiments appear to show that the susceptibility of the seminal vesicles to androgen is persistently interfered with by neonatal injections of estrogen. There was no difference in degree of the susceptibility among the seminal vesicles with or without metaplastic epithelium. This may suggests that the sex 
steroid-binding ability of the seminal vesicles is lowered by neonatal estrogen treatment, as has been reported in the uterus and vagina of neonatally estrogenized mice (Terenius et al., 1969; Shyamala et al., 1974).

Takasugi and Furukawa (1972) and Takasugi and Mitsuhashi (1972) found that testicular lesions which would take place in mice given neonatal injections with estrogen were prevented if androgen or gonadotropins were administered concurrently with estrogen. However, the present experiments have shown that androgen and/or gonadotropins fail to exert any marked ameliorating effects on the testis, when administered after neonatal estrogen treatment.

On the basis of the present findings, in addition to bringing about an irreversible alteration in the hypothalamo-hypophysial axis (Mori, 1967), estrogen appears to act directly on the testis of neonatal mice, causing a permanent impairment of spermatogenic capacity. As compared with estrogen, the effect of androgen seems to be less important. It may be of some interest to note that the testicular interstitial tissue remained atrophic in the neonatally androgenized mice given TP plus PMS, while it was hyperplastic in neonatally estrogenized mice similarly treated. In view of the report that PMS has some stimulatory effects upon testicular interstitial cells in immature rats (Chemes et al., 1976), androgen administration may exert more marked effects on interstitial cells rather than on seminiferous tubules in neonatal mice.

\section{Acknowledgements}

The author wishes to thank Emeritus Professor K. Takewaki of the University of Tokyo and Professor N. Takasugi of Okayama University for their valuable advice and critical reading of the manuscript.

\section{References}

Chemes, H. E., M. A. Rivarola and C. Bergada (1976). J. Reprod. Fert. 46, 283.

Mori, T. (1967). J. Fac. Sci. Univ. Tokyo, Sec. IV 11, 243.

Ohta, Y. (1975). Annot. Zool. Japon. 48, 96.

Ohta, Y. (1976). Ibid. 49, 227

Ohta, Y. and N. Takasuki (1974). Endocrinol. Japon. 21, 183.

Oštádalvá, I., A. Babicý, Z. Lojda, M. Kolář, Z. Deyl and J. Pařizek Proc. of Symp. on "The Postnatal Development of Phenotype" (edited by Kazda, S. and V. H. Denenberg). Academia, Prague, p. 267 (1970).

Shyamala, G., T. Mori and H. A. Bern (1974). $J$. Endocr. 63, 275.

Takasugi, N. (1970). Endocrinol. Japon. 17, 277.

Takasugi, N. and M. Furukawa (1972). Ibid. 19, 417.

Takasugi, N. and Y. Mitsuhashi (1972). Ibid. 19, 423.

Terenius, L., B. J. Meyerson and A. Palis (1969). Acta Endocr. 62, 671. 